\title{
Functional Contentment Model: Optimizing Quality of Life for Nursing Home Residents with Dementia
}

\author{
Daniel M. Pierce', Marilyn R. Gugliucci², Shirley A. Weaver ${ }^{3}$ \\ ${ }^{1}$ MatureCare, Department of Primary Care, University of New England College of Osteopathic Medicine, Biddeford, ME, USA \\ ${ }^{2}$ Division of Geriatrics, Department of Primary Care, University of New England College of Osteopathic Medicine, Biddeford, \\ ME, USA \\ ${ }^{3}$ University of New England College of Osteopathic Medicine (Retired), Biddeford, ME, USA \\ Email:mgugliucci@une.edu
}

How to cite this paper: Pierce, D.M., Gugliucci, M.R. and Weaver, S.A. (2019) Functional Contentment Model: Optimizing Quality of Life for Nursing Home Residents with Dementia. International Journal of Clinical Medicine, 10, 439-451.

https://doi.org/10.4236/ijcm.2019.109037

Received: August 10, 2019

Accepted: September 15, 2019

Published: September 18, 2019

Copyright (c) 2019 by author(s) and Scientific Research Publishing Inc. This work is licensed under the Creative Commons Attribution International License (CC BY 4.0).

http://creativecommons.org/licenses/by/4.0/

\begin{abstract}
The Functional Contentment Model (FCM) attains two objectives: 1) building a relationship focused plan of care for nursing home residents diagnosed with dementia; and 2) maximizing and maintaining older adults' contentment, peace, and happiness while living in dementia care environments. There are three essential components within the FCM: 1) Person/Family Centered Care; 2) Slow Medicine; and 3) Team Care Management. The principles of "Person/Family-Centered Care" are coupled with the philosophy of "Slow Medicine," and neither can exist without the engagement of "Team Care Management." In short, the FCM maximizes the older adult's potential functioning in activities of daily living, cognition, gross and fine motor skills, communication, and physical well-being, while maintaining the highest possible level of contentment, peace, and happiness. This is accomplished through dynamically utilized professional modalities adapted to the changing needs of the older adult resident-pharmacologic, physical and occupational therapies, family education and involvement, dietary, spiritual, stimulating activities, as well as any individualized modality. The lead for operationalizing the Functional Contentment Model is the nursing home medical director, whose key role is assuring a team approach to care including the older adult resident, the family, and all staff (dietary, housekeeping maintenance as well as care and administrative staff). The FCM is a culture change model that has implications in practice and policy for each nursing home.
\end{abstract}

\section{Keywords}

Dementia Care, Functional Contentment, Nursing Home, Person-Centered Care 


\section{Introduction}

Residents with dementia often pose a challenge to providing person-centered care for long-term care residential environment administrators, staff, and medical directors. Historically, we have not done well in meeting this challenge, as evidenced by less than optimal resident quality of life, family satisfaction, and staff satisfaction and retention [1] [2] [3]. By utilizing a creative approach to person-centered care, built on new models of medical practice and team care, we can improve the quality of life for nursing home residents with dementia, their family care partners, and the staff. This article introduces the Functional Contentment Model (FCM) developed at the University of New England College of Osteopathic Medicine Mature Care Practice in Maine, USA. MatureCare provides medical directorship and patient care to residents and skilled rehabilitation patients in 15 nursing homes. The primary goal of the Functional Contentment Model of care is functional contentment of the resident with dementia; exhibited through actions that convey a sense of purpose, calm, and feeling at peace. Secondary outcomes include increased satisfaction of family members, direct and indirect care staff, and nursing home professional staff and practitioners.

Of the total U.S. population, one in ten people (10 percent) age 65 and older has Alzheimer's dementia or related dementias [4] [5] - a predictor of eventual need for long-term care supports and services. As of 2012, more than 5 million Americans had the disease. By 2050, the prediction is this number will grow to 16 million. The percentage of people with dementia increases with age; 3 percent of people age $65-74,17$ percent of people age $75-84$, and 32 percent of people age 85 and older have Alzheimer's or related dementia [5]. There is a direct link between disease and the need for nursing home care. Admission by age 80 is expected for $75 \%$ of people with dementia compared with only 4 percent of the general population. [6]. Overall, 50\% of nursing home residents have Alzheimer's or related dementia [7]. In Maine, the oldest state (44.5 average age) in the union, the number of persons living with dementia is estimated to increase from 37,000 individuals in 2012 to over 53,000 individuals by 2020 [8]. In 2012, 58\% of Maine nursing home residents had dementia and nearly half (44\%) of the people receiving community and facility-based long-term services and supports (LTSS) had dementia [7]. It is essential with the rise in nursing home residential care for people with dementia that we instill sound models of care in their environments. Proper care will benefit the older adult, his/her family and nursing home staff/practitioners.

\section{Functional Contentment Model Methods}

\subsection{Three Essential Components}

Within the Functional Contentment Model (FCM), one must consider three essential components: 1) Person/Family Centered Care; 2) Slow Medicine; and 3) Team Care Management (see Figure 1: Functional Contentment Model). The principles of "Person/Family-Centered Care" are coupled with the philosophy of 


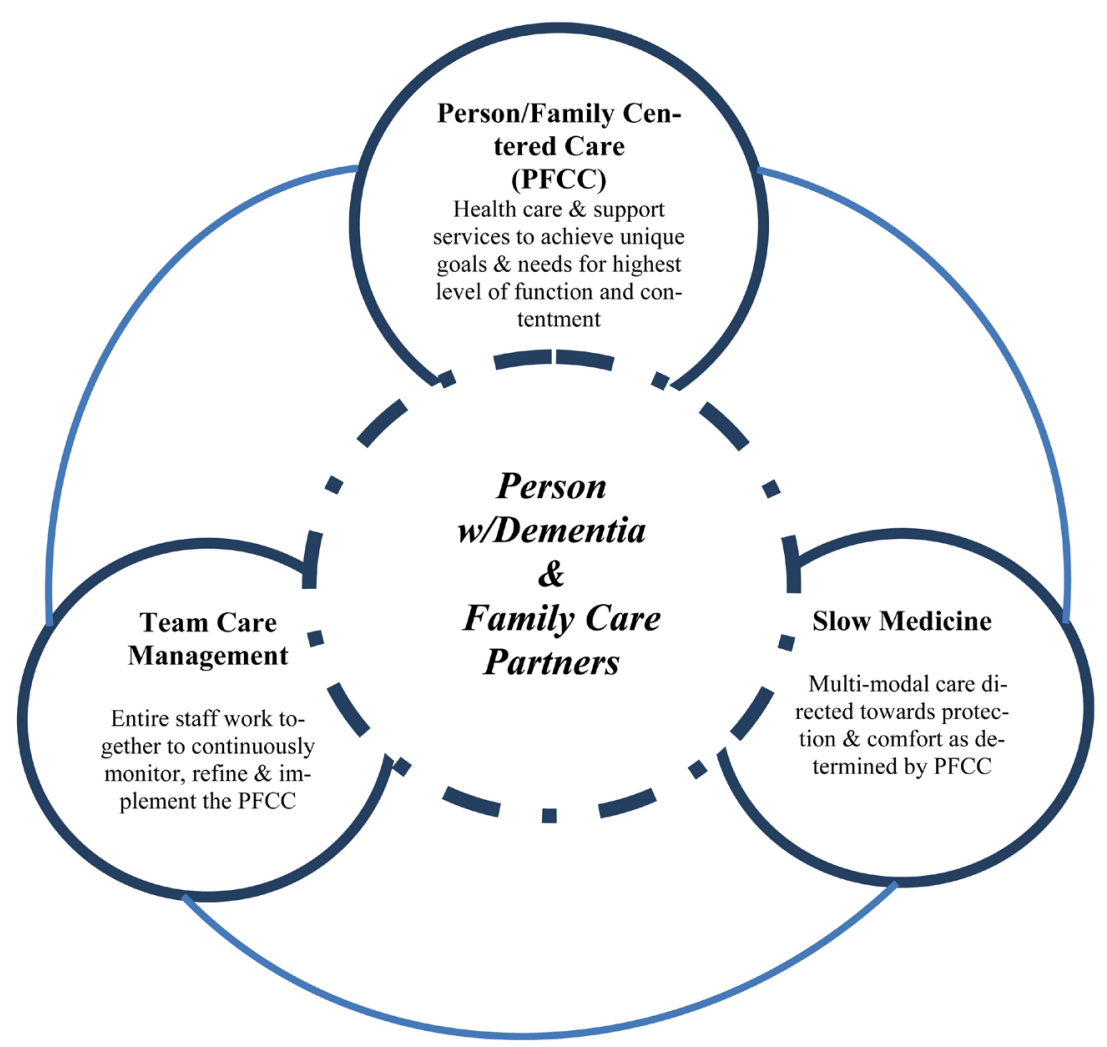

Figure 1. Functional contentment model.

"Slow Medicine," and neither can exist without the engagement of "Team Care Management." In the FCM, "functional" is defined as: of or having a special activity, purpose, or task; designed to be practical and useful, rather than attractive [9]. "Contentment" is defined as: a state of happiness and satisfaction [9] [10].

1) Person/Family Centered Care (PFCC): Person/Family Centered Care generally refers to an orientation to the delivery of health care and supportive services that considers the older adult's needs, goals, preferences, cultural traditions, family situation, and values [11]. The resident is the key member of the team with the family at the center as well. Continuous monitoring of the resident's experience of care (feelings or expressions about the care) as well as the family's experience is essential to a congruent care plan for the resident. Within person/family centered care, the care team includes the health professionals, social service professionals, direct care staff, and support staff such as housekeeping, food service, and maintenance. Services and supports are delivered from the perspective of the resident [11]. For nursing home residents with cognitive impairment, the family care partner(s) engagement is integral to achieving person/family centered care. This concept holds true even if the family is not the biologic family but a health care power of attorney (POA) or support person of choice by the resident. Family/POA involvement in the planning process helps the care team know the resident's personhood, personal needs, wants, capacity, and expression of autonomy; all factors important for creating a successful care plan. Family care partners may recognize changes that indicate a decrease in 
resident function and/or contentment; both signs that can guide changes in the care plan to attain functional contentment.

To be clear, the FCM does not advocate for formal care management team meetings in which the resident is at the table as a participant. Instead, two options are possible depending on the level of cognitive impairment: First, for residents with early to moderate cognitive impairment, they possess the capacity to express daily preferences for care and should be encouraged to discuss their everyday care wishes with their family and the care team in a natural setting. Second, for residents at the later stages of cognitive impairment, the resident may communicate his/her autonomy through behavior, which the family and care team must learn to translate to specific care plans. Understanding these expressions and behavioral cues for residents in the mid or later stages of dementia, along with familial/care partner input, is the first important step to achieving Person/Family Centered Care as part of the Functional Contentment Model.

2) Slow Medicine: Slow Medicine for care of older adults, a concept published by Dr. Dennis McCullough, geriatrician, is directed towards the protection and comfort of the older person rather than cure of an ailment [12]. According to McCullough, "Slow Medicine embraces the unsung work of daily attention that is the greatest need and firmest foundation for longevity and quality of life at the farthest reach of age" ([12], p.xxi). It focuses attention on older persons and their specific challenges and needs; including family wishes to ensure congruent care regardless of the medical setting. Slow Medicine is an intentional plan for a) understanding the older adult's physical/cognitive/emotional needs, medical diagnoses, values, life, choices, and living circumstances; b) caring about the older person and his/her family; and c) living well as determined by the older adult, the family and the provider. Based on the belief that the best decisions about care come from a measured approach; collecting information and moving forward slowly while continually reassessing is key [12]. The philosophy and practice of Slow Medicine serves older adults well because their journey of late life is more complicated than that of middle age. Factors like the older person's stage in life, strength, and the severity of the ailment play a vital role in the practice of Slow Medicine. Dr. McCullough stated that a successful outcome in the care of an older person was based on the repeated assessment of the choices of the older person and his/her family [12]. To enrich an older person's life to the end, Dr. McCullough identified five fundamental principles to guide families, health professionals, caregivers, and other care team people:

a) Understand older persons deeply - their complexity, acknowledging losses and newly revealed strengths that come with aging.

b) Accept the need for interdependence while promoting mutual trust.

c) Learn to communicate well and with patience.

d) Make a covenant for steadfast advocacy-the doctor becomes the dedicated "agent" for the older adult and the family; although unwritten and often unspoken, she/he will be there in the time of need.

e) Maintain an attitude of kindness no matter what-days of caregiving 
are often long and difficult requiring patience and forbearance when there appears to be a seemingly endless cycle of chores ([12], Excerpt pp. 3-12). With these five principles in mind, the family, the medical director, and the nursing home staff have a responsibility to each other and the older person to provide mindful care.

3) Team Care Management: A well designed and managed care team for each resident with dementia is an essential component of the Functional Contentment Model. Staff stability is important to the resident's development of trust, comfort, and sense of safety. Staff's depth of understanding of the person they care for or encounter during their duties provides opportunities for consistent interactions with residents. The staff's ability to recognize and report subtle changes in a resident's health, comfort, actions, and function should be standard practice for each staff member. Honoring the insights and input of maintenance, housekeeping and dietary staff as much as the health and service providers are central to recognizing and responding to the resident's care needs.

The Team Care Management approach is described as: "a work group that is made up of individuals who see themselves and who are seen by others, as a social entity who are interdependent because of the task they perform as members of a group, and who perform tasks that affect others" ([13], p.308). Studies in a variety of work environments have shown that there are several potential benefits associated with team organizing, including greater job satisfaction, greater commitment, and greater effectiveness and quality [13]. However, the nursing home setting is unique as is the care for residents with dementia. In three studies conducted by Havig et al. [14] [15] [16] on team care management and workgroups, all three studies revealed that active leadership, represented by task- and relationship-oriented leadership styles, and the use of teams or workgroups, are related to higher quality of care in nursing homes [14] [15] [16]. In the last study Havig et al. [16] conducted, they found that functional teams/work groups were found to be effective when each member: 1) assumes ownership, 2) perceives an insider status, and 3) shares mental models. Active leadership is dependent on work ethic, work environment, professionalism, and organizational vision [16]. In essence, the studies have noted that enhanced success for workgroups and active leadership in a variety of long-term care settings each included engagement, feeling a sense of contribution, camaraderie, being included in care processes, exhibiting a good work ethic, and upholding the nursing home philosophy of professionalism [16]. Teamwork has an especially important meaning in a successful older adult care partner process. Including residents and their representatives into the decision-making process creates better information flow and consultation procedures to achieve a true dialogue both within the team and with the residents and family (see Figure 2: Functional Contentment Team Care Management Model) [17].

\subsection{Operationalizing the Functional Contentment Model}

In short, the Functional Contentment Model (FCM) is a relationship building 


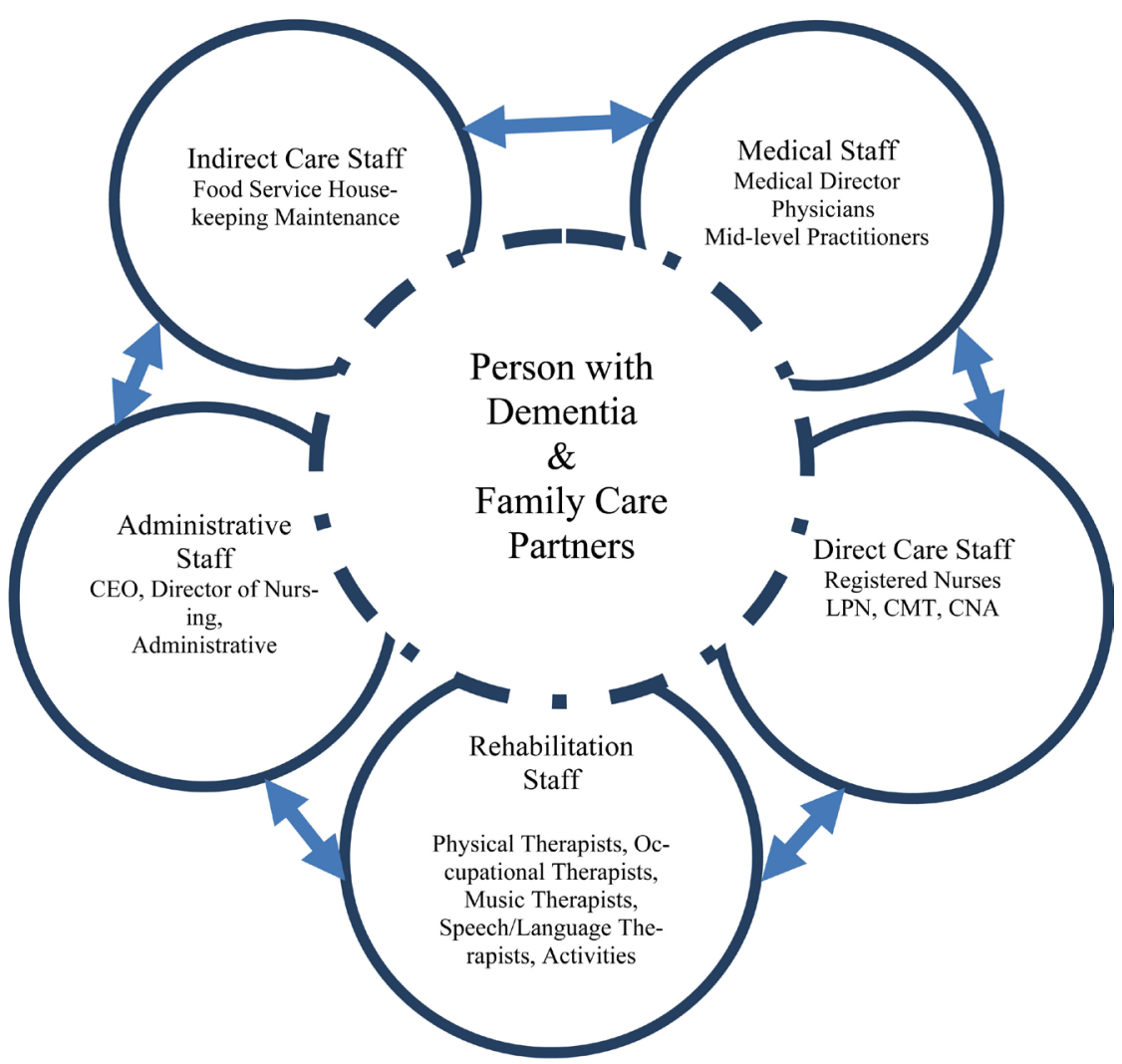

Figure 2. Functional contentment team care management model.

plan of care with the goal of maximizing the older adult's potential functioning in activities of daily living, cognition, gross and fine motor skills, communication, and physical well-being, while maintaining the highest possible level of contentment, peace, and happiness. This is accomplished through dynamically utilized professional modalities adapted to the changing needs of the older adult-pharmacologic, physical and occupational therapies, manipulative therapy, family education and involvement, dietary, spiritual, stimulating activities (memory), as well as any individualized modality. The lead for operationalizing the FCM is the nursing home medical director, whose key role is assuring a team approach to care. Every staff member in the nursing home (including maintenance, cleaning, and dietary/food service staff) as well as family and friends and of course the resident makes up the team approach to care.

\subsection{Clinical Assessment Elements of the Functional Contentment Model}

There are seven clinical assessment elements that are paramount to the Functional Contentment Model (see Table 1: Checklist for the Functional Contentment Model Assessments). The continuous reflection on and across these seven clinical assessments with each older adult is fundamental to recognizing his/her autonomy that contributes to functional contentment.

Below, each clinical assessment element is listed and defined based on the 
Table 1. Checklist for the functional contentment model assessments.

\begin{tabular}{|c|c|c|}
\hline Check & 7 FCM Components & Who Assesses and/or Supports \\
\hline & Life History & $\begin{array}{l}\text { Resident, Health and Service Staff, Family and All } \\
\text { Staff }\end{array}$ \\
\hline & Comorbidities & Health Providers and Care Staff \\
\hline & Medication Evaluation-Benefit/Risk & Pharmacy/Health Providers \\
\hline & Physical Abilities & $\begin{array}{l}\text { Physical, Occupational, and Speech/Language } \\
\text { Therapists }\end{array}$ \\
\hline & Cognitive Abilities & $\begin{array}{l}\text { Resident, Family, Health Providers w/ Support of } \\
\text { All Staff }\end{array}$ \\
\hline & Support System & Resident, Family, Social Services and All Others \\
\hline & $\begin{array}{l}\text { "Living a Full Life to the Very End" } \\
\text { Plan/End of Life Plan }\end{array}$ & $\begin{array}{l}\text { Resident, Family, Social Services, Chaplain, } \\
\text { Health Providers }\end{array}$ \\
\hline
\end{tabular}

Functional Contentment Model:

Life History: The life history is foundational and all staff need to be facile with what questions to ask to ascertain a conversational life history. The more staff know and share about the resident, the more able they are to meet the person's functional needs and maximize his/her contentment.

Co-Morbidities: The diagnosis of dementia is one among other medical diagnoses for the nursing home resident; awareness of all diagnoses and associated treatments (pharmacologic/non pharmacologic) are to be weighed relative to the other six clinical assessment elements, adjusting the FCM care plan accordingly.

Physical Abilities: The resident's physical function and ensuring optimization of desired function contribute towards a sense of peace, happiness, and wellbeing.

Cognitive Abilities: The level of dementia and its progression is baseline information. The plan associated with cognitive abilities needs to be adapted continually as the resident transitions. The care management team requires guidance by the medical director regarding what to look for and how to document observations on individual residents.

Support System: The resident with dementia can be supported in a variety of ways; including but not limited to, family, friends, nursing home staff, or a stuffed or real pet (depending on the home). Each person who is part of the overall support system plays a role in maximizing the older adult's function and contentment.

Medication Evaluation-Benefit/Risk: The resident's medications require periodic reviews; determining how each contributes to optimizing or compromising functional contentment and modifying medication regimens is essential to resident function and contentment.

Living a Full Life to the Very End/End of Life Plan: The individual's life plan may be firm or emerge through time in the care setting. However, the earlier the resident's end of life plan is accepted for living a full life to the very end [18]; the more congruent the Functional Contentment Model roadmap of care supports 
the philosophy of the resident until his/her final breath.

There is no set order for implementation of each FCM element. The Functional Contentment Model requires that each of the seven clinical assessment elements is reviewed and adapted when any member of the care management team observe changes in the resident. Success can be determined by assessing the need for fewer or no mood stabilizers; fewer or no behavioral outbursts; improved appetite; improved sleeping patterns; participation in activities if able; allowing staff to provide personal care.

\section{Functional Contentment Case Study}

The following case, a patient of the first author, illustrates how the Functional Contentment Model optimized care for Mrs. Joan Doe. Upon admission, the following was determined for Mrs. Doe. The FCM implementation is then presented further below (Section 4).

\section{Patient Description}

Joan Doe is an 81-year-old (at admission) female and married. Her height is 5'3" and she weighs $127 \mathrm{lbs}$. She was born and raised in Maine and educated in Massachusetts. She received a Bachelor's degree in Education and a Master's Degree in Special Education. She married Ernest in 1959 at age 24 and had 2 children, Dan and Sarah. They moved to Maine in 1969. Ernest owned a motor repair company while Joan taught Special Education and eventually served as Special Education Director for many years at a local high school. Her hobbies included gardening and baking. She always prided herself on being well dressed and "proper" in her behavior. She admitted to long-standing social anxiety and being most comfortable with family and friends. In her early 70's, Joan became increasing reclusive, anxious and forgetful. As her memory declined and her anxiety increased, it became more and more difficult for Joan to have her needs met at home.

\section{1) Case History}

Mrs. Doe's pre-existing condition was progressive dementia over the past seven years. She is unable to care for herself independently due to cognitive decline, has urinary and bowel incontinence, and impaired communication secondary to altered mental status. At the age of 78 , she was first admitted to a nursing home; but after 3 years that nursing home was unable to meet her needs as her dementia increased and her self-attentiveness decreased. She moved to the memory care environment at the current nursing home, which is located 35 miles from her home where her husband resides.

\section{2) Diagnoses}

Cognitive Impairment; Hypertension; Hyperlipidemia, Hypothyroidism; Urinary/Bowel Incontinence, and Osteoarthritis.

\section{3) Medications}

a) Lipitor $20 \mathrm{mg}$ po q day; b) Lisinopril $10 \mathrm{mg}$ po q day; c) Risperdal $1 \mathrm{mg}$ po bid; d) Ativan $0.5 \mathrm{mg}$ po q 6 hours prn; e) Ambien $5 \mathrm{mg}$ po q hs prn; f) Meto- 
proplol $50 \mathrm{mg}$ po bid; g) Synthroid $125 \mathrm{mcg}$ po q day; h) Namenda $10 \mathrm{mg}$ po bid; i) Aricept $10 \mathrm{mg}$ po q day; j) Senna s 1 po bid; k) Vitamin D 1000 IU po q day; 1) Tylenol 650 mg po q 6 hours; m) Multi vitamin q day.

\section{4) Daily Function}

Mrs. Doe ambulates short distances with walker and one assist, but primarily is wheel chair reliant. She is essentially aphasic with occasional yelling out. She is unable to transfer without $1-2$ assist. Mrs. Doe is toileted regularly; she is incontinent of both urine and feces. The MOCA (Montreal Cognitive Assessment) score was 5 out of a possible 30. Mrs. Doe was unable to perform the PHQ 9. She shows intermittent recognition of husband (who is there daily for at least 10 hours/day), but rarely recognizes children (who are involved in care planning but visit usually once a week). She is resistant to care. Unable to perform any Activities of Daily Living (ADLs) including feeding herself.

5) End of Life Plan

Full Code without POLST (Physician Orders for Life Sustaining Treatment); husband is health care power of attorney.

\section{Implementation of the Functional Contentment Model for Mrs. Doe}

Based on the information provided in Mrs. Doe's case study, the first step is to review the seven clinical assessment elements of the Functional Contentment Model (see Table 2 for details) and adapt or adjust each according to the three components of the FCM; Person/Family Center Care, Slow Medicine, and Care Team Management.

\section{Case Results}

Mrs. Doe was a relatively uncomplicated nursing home resident except for early bouts of yelling and her resistance to assistance with her Activities of Daily Living by staff. Her dementia was severe and yet the adverse behaviors reduced as she responded well to the team effort to maximize her function and contentment. A set staff team was assigned to Mrs. Doe to maintain continuity of care through day and evening shifts; midweek and weekends. Through application of the Functional Contentment Model she became more engaged with staff and family and was more pleasant when assisted with Activities of Daily Living, such as bathing, grooming, and eating. Mrs. Doe appeared more relaxed, especially with her robotic puppy, and participated, or at least tolerated a variety of activities. Her husband, with time, felt less compelled to be at her side 10 hours a day, and began to come later and leave earlier; he even resumed his twice-weekly golf game, which he had abandoned for several years. Morale was positive for the staff including the service staff who knew that Mrs. Doe preferred their company.

Mrs. Doe died peacefully 26 months after the implementation of the FCM in the Memory Care environment. Her husband and children felt that she had finished her life with contentment, which brought them a sense of peace. 
Table 2. Seven clinical assessments of Mrs. Doe's functional contentment.

$\begin{array}{lc}\text { Seven Clinical Assessments } & \text { Functional Contentment Team } \\ \text { of Functional Contentment } & \text { Management Plan Considerations }\end{array}$

The life history provides the foundation for Mrs. Doe's life. Let the life history morph into a dynamic life story that creates a bridge to

Life History/Preferences the present. Create a list and post it by her door (include Mrs. Doe if feasible) that includes key points about who she was, what she prefers now, what her desires are (foods, spirituality, music, etc), and what her special needs are (glasses, assistive devices, etc).

Mrs. Doe's medical history is without catastrophic events and ill-

Co-Morbidities nesses. Her physical exam confirmed that she was a relatively healthy 81 years old. The FCM focus is her cognitive impairment, incontinence, hypothyroidism, and osteoarthritis.

Mr. Doe (husband) agreed that essential medication should include only those that would provide her comfort (contentment). Synthroid continued for hypothyroidism to avoid the discomfort of a hypothyroid state. Lipitor, Lisinopril, Metoprolol, Vitamin D, and the Multivitamin were titrated where necessary and discontinued. Ambien was titrated and discontinued without difference in sleep patterns. Aricept and Namenda were discontinued to allow Mrs. Doe to be in a natural state. Tylenol and Senna-s are now given in the Medication Evaluation evening.

After two weeks of "settling in" the Ativan was discontinued for non-use once non-pharmacologic interventions were in place, such as iPod music therapy and robotic pet (puppy) companionship. Metoprolol and Risperdal were titrated and discontinued and Mrs. Doe exhibited an increase in energy. Adhering to the Slow Medicine philosophy, nine of the previous 13 medications were discontinued over a two-week period; appearing to not adversely affect Mrs. Doe or her behaviors.

Physical Therapy, Occupational Therapy, and Speech/Language Therapy evaluated Mrs. Doe's physical abilities and each

Physical Abilities professional staff developed goals and a plan for her during her stay that matched the proposed goals for the Person/Family Centered Care plan.

Despite the low score on the MOCA, the increase in energy from decreasing certain medications and the implementation of the

Cognitive Abilities non-pharmacologic interventions, Mrs. Doe's contentment continued as did her recognition of her husband. Her "yelling out" ceased with the increase in contentment.

FCM care management team developed a picture of Mrs. Doe's previous support system and what parts of that system remained or needed to be added. It was determined that Mrs. Doe had a favorite

Support System housekeeper and food service worker. Efforts were made to ensure these staff members had time with Mrs. Doe. The robotic puppy calmed her and members of the Care Team, including her children, learned skills to support Mrs. Doe during their time together.

Mr. Doe continued as Health Care POA. The medical director had educational conversations with Mr. Doe and introduced the POLST

Living a Full Life to the Very form. Mr. Doe shared the information with his children and within End/End of Life Plan two weeks he had decided to complete a POLST form which indicated comfort care, while maintaining only medications that were essential for comfort. 


\section{Discussion}

The Functional Contentment Model is a multidimensional care model. Those of us in nursing home care know that each resident is multifaceted with distinct personalities and individual needs. The traditional medical, social, and physical examination and review of recent and past medical interventions is fundamental to good medical care, but insufficient when considering the contentment of the resident with dementia and his/her family. The Functional Contentment Model approach to care requires that staff in every capacity have an appreciation of the resident's personhood and how that person defines quality of life-the meaningful life experiences, preferences, social supports, etc.- as may be evidenced by photos and other personal artifacts, family information, inter-personal communications, desires, and behavior. Through continuous accumulation of the resident's life story focused on Person/Family Centered Care, adjustments to services/approaches to meet the needs and wants of the resident will be more effective, even as cognitive function changes. Slow Medicine simplifies interventions, reducing/discontinuing those medications that are not contributing to resident well-being or improving function, while supporting communication, patience, and full care. Team Care Management, in the broadest sense of team, provides opportunities for all staff along with the resident and the family to have a role in establishing resident function and contentment.

\section{Clinical Implications}

- The goal is to find ways to create joy and well-being with each resident with dementia.

- The biggest challenge for successfully maximizing a resident's function and contentment is the dementia and its progression; therefore, challenges for FCM successful implementation is "buy in" from the family and nursing home staff-it takes a team to make this work and the more involvement by all connected with the resident the better.

- The implementation of the three components and seven FCM clinical assessment elements provides a fresh approach to resident care and well-being; focusing on the resident and family goals.

- Reframing the traditional medical model of identifying the resident "problem list" to focus on the resident's capacity, desires, and well-being within the FCM seven elements builds a quality of life network for that resident that also aids staff satisfaction.

- The Functional Contentment Model is a culture change model that has implications in practice and policy for each nursing home.

- Research on the FCM is warranted; the suggestion is to conduct qualitative case study research on individual residents and as more cases are documented, to then include pre/post survey and focus group interviews with nursing home staff and families.

- This iterative process for creating culture change is manageable, affordable, 
person-centered, and progressive.

\section{Conflicts of Interest}

The authors declare no conflicts of interest regarding the publication of this paper.

\section{References}

[1] Zimmerman, S., Williams, C.S., Reed, P.S., Boustani, M., Preisser, J.S., et al. (2005) Attitudes, Stress, and Satisfaction of Staff Who Care for Residents with Dementia. The Gerontological Society of America: The Gerontologist, 45, 96-105. https://doi.org/10.1093/geront/45.suppl_1.96

[2] Institute for the Future of Aging Services (2007) The Long-Term Care Workforce: Can the Crisis Be Fixed? Problems, Causes and Options. Washington DC.

[3] National Commission for Quality Long-Term Care (2006) Out of Isolation: A Vision for Long Term Care in America. Washington DC.

[4] Ortman, J.M., Velkoff, V.A. and Hogan, H. (2014) An Aging Nation: The Older Population in the United States, Current Population Reports. U.S. Census Bureau, Washington DC, 25-1140.

http://www.census.gov/content/dam/Census/library/publications/2014/demo/p25-1 140.pdf

[5] Hebert, L.E., Weuve, J., Scherr, P.A. and Evans, D.A. (2013) Alzheimer Disease in the United States (2010-2050) Estimated Using the 2010 Census. Neurology, 80, 1778-1783. https://doi.org/10.1212/WNL.0b013e31828726f5

[6] Alzheimer's Association (2019) Alzheimer's Disease Facts and Figures. Alzheimer's Dementia, 15, 321-387. https://doi.org/10.1016/j.jalz.2019.01.010

[7] Harris-Kojetin, L., Sengupta, M., Park-Lee, E., Valverde, R., et al. (2016) Long-Term Care Providers and Services Users in the United States: Data from the National Study of Long-Term Care Providers, 2013-2014. Vital \& Health Statistics, No. 38, $1-105$.

[8] Maine Department of Aging and Disability Services (2012) State Plan for Alzheimer's Disease and Related Dementias in Maine.

[9] (1989) Oxford Dictionary. 2nd Edition, Oxford University Press, Oxford. http://www.oxforddictionaries.com/us/definition/american_english/contentment

[10] Interprofessional Education Collaborative Expert Panel (2011) Core Competencies for Interprofessional Collaborative Practice: Report of an Expert Panel. Interprofessional Education Collaborative, Washington DC.

[11] Feinberg, L. (2012) Moving toward Person- and Family-Centered Care. AARP Public Policy Institute Insight on the Issues 60.

[12] McCullough, D. (2009) My Mother, Your Mother: Embracing "Slow Medicine," the Compassionate Approach to Caring for Your Aging Loved Ones. Harper Perennial/HarperCollins Publishers, New York. https://doi.org/10.1089/acm.2008.0256

[13] Guzzo, R.A. and Dickson, M.W. (1996) Teams in Organizations: Recent Research on Performance and Effectiveness. Annual Review of Psychology, 47, 307-338. https://doi.org/10.1146/annurev.psych.47.1.307

[14] Havig, A.K., Skogstad, A., Kjekshus, L.E. and Romøren, T.I. (2011) Leadership, Staffing and Quality of Care in Nursing Homes. BMC Health Services Research, 11, 327. https://doi.org/10.1186/1472-6963-11-327 
[15] Havig, A.K., Skogstad, A., Veenstra, M. and Romoren, T.I. (2013) Real Teams and Their Effect on the Quality of Care in Nursing Homes. BMC Health Services Research, 13, 499. https://doi.org/10.1186/1472-6963-13-499

[16] Havig, A.K. and Hollister, B. (2017) How Does Leadership Influence Quality of Care? Towards a Model of Leadership and the Organization of Work in Nursing Homes. Ageing International, 43, 366-389. https://doi.org/10.1007/s12126-017-9304-8

[17] Pitkälä, K.H., Niemi, M. and Suomivuori, L. (2003) Development of a Geriatric Team: A Staff Development Educational Process in a Nursing Home. Educational Gerontology, 29, 117-128. https://doi.org/10.1080/713844285

[18] Gawande, A. (2014) Being Mortal: Medicine and What Matters in the End. Henry Holt and Co., New York. 